\title{
Flood Resilience Building in Thailand: Assessing Progress and the Effect of Leadership
}

\author{
Somporn Khunwishit ${ }^{1} \cdot$ Chanisada Choosuk $^{2} \cdot$ Gary Webb $^{3}$
}

Published online: 5 March 2018

(C) The Author(s) 2018. This article is an open access publication

\begin{abstract}
Disaster risk reduction has become a global strategy for making cities more resilient since the establishment of the Hyogo Framework for Action in 2005. The question that still challenges emergency management scholars and professionals, however, is what contributes to the progress of resilience building. Previous literature suggests that disaster resilience can be attributable to multiple factors, including leadership. But the specific abilities that help leaders promote resilience have not yet been examined empirically. To address this problem, using the United Nations International Strategy for Disaster Reduction 10 Essentials for Making Cities Resilient as guidelines, we assessed the progress of flood resilience building in Thailand and its relationship to local government leaders' abilities. Our research showed that, since the flood disaster in 2011, municipalities in Thailand have made moderate progress in flood resilience building. The results of a multiple regression analysis revealed that disaster resilience leadership abilities have had a statistically significant, positive effect on the progress of flood resilience building. Our findings underscore the role of leadership in making cities more resilient and shed light on how local government leaders can contribute to the progress of
\end{abstract}

Somporn Khunwishit

somporn.kh@psu.ac.th

1 Faculty of Management Sciences, Prince of Songkla University, Hat Yai District, Songkhla Province 90112, Thailand

2 Faculty of Environmental Management, Prince of Songkla University, Hat Yai District, Songkhla Province 90112, Thailand

3 Emergency Management and Disaster Science (EMDS) Department, College of Health and Public Service, University of North Texas, Denton, TX 76201, USA disaster risk reduction. We also outline the academic implications and practical contributions of our research.

Keywords Disaster management - Disaster resilience leadership - Disaster risk reduction · Flood resilience building . Thailand

\section{Introduction}

For decades, earthquakes, floods, storms, and other climate-related crises have become major sources of property damage and fatalities around the world. These extreme events have not only increased in frequency, but also in severity. The United Nations International Strategy for Disaster Reduction (UNISDR) has reported that, from 2000 to 2012, natural hazard-induced disasters caused a total damage of about 1.7 trillion U.S. dollars, affected 2.9 billion people, and killed 1.2 million people around the world. That means, each year, natural hazard-induced disasters caused a total damage of about 13.1 billion U.S. dollars, affected 223 million people, and killed more than 92 thousand people (UNISDR 2012a). Examples of catastrophes that have produced devastating impacts within the last 15 years are the 2004 Indian Ocean tsunami, Hurricane Katrina in 2005, super cyclone Nargis in Myanmar in 2008, the 2008 Sichuan Earthquake in China, the 2011 East Japan Earthquake and Tsunami, typhoon Haiyan that hit the Philippines in 2013, and the 2015 earthquake in Nepal. These increases in the frequency and impacts of disasters have made city resilience building much more important at the global level.

In 2005, when the Hyogo Framework for Action 2005-2015: Building the Resilience of Nations and Communities to Disasters (HFA) (UNISDR 2005) was 
established, disaster risk reduction (DRR) was formally acknowledged worldwide as the new approach to managing disasters at both local and national levels. In 2010, UNISDR launched the "Making Cities Resilient (MCR)" campaign to encourage local government leaders around the world to adopt disaster risk reduction as an approach to reducing disaster risks and building resilience for their cities. As of 26 February 2018, more than 3850 cities had signed up to participate in the campaign (UNISDR 2017). This gradual increase in the number of cities participating in the MCR campaign suggests that the disaster risk reduction approach to disaster management has become increasingly accepted as the new, sustainable, and more effective way of managing disasters by those who are involved in city management.

However, the risk reduction approach is not without flaws. Although the efficacy of the disaster risk reduction approach in minimizing risk and increasing the coping capacity of cities is widely recognized, implementing disaster risk reduction and resilience building strategies is quite challenging and their achievements have thus varied. For example, for 2011, the World Bank reported disaster risk reduction progress scores of 168 countries that have adopted the Hyogo Framework for Action (HFA) since 2005. Disaster risk reduction progress was assessed by scores that ranged from 1 (worst) to 5 (best or most progress). The report showed that only a few countries had made good progress (scores of 4.5 and above), while more than half of the countries had made only moderate or little progress (World Bank 2017).

Hence, it is important to understand the factors that support the successful implementation of disaster risk reduction and resilience building. When it comes to disaster management, it is inevitable that local government leaders play a key role in leading and coordinating a variety of tasks and operations. Thus, in this research, we focus on leadership factors and their effects on the disaster resilience of a city. Our research question is simple: can city resilience be enhanced by leadership?

\section{Literature Review}

To examine flood resilience building progress in Thailand, literature and previous studies on disaster resilience, resilience enhancing factors, and the role of leadership in disaster management were reviewed. This review of the literature and related studies was used as the basis for hypothesis formulating and testing the relationships among selected variables.

\subsection{Disaster Resilience}

Resilience is "the capacity of any entity-an individual, a community, an organization, or a natural system-to prepare for disruptions, to recover from shocks and stresses, and to adapt and grow from a disruptive experience" (Rodin 2014, p. 3). The term is often used interchangeably with such terms as community resilience and city resilience. One of the earlier works, in the academic world, that empirically examined community or disaster resilience is a research conducted by Paton and Johnston (2001). Since then, disaster resilience has gradually gained attention from disaster management scholars. For more than a decade, disaster resilience scholars have been interested in explaining how social units such as groups, organizations, and communities effectively cope with sudden shocks, and in identifying the factors that contribute to adaptive capacities.

In the practical realm, however, disaster resilience has only recently become an international agenda within the HFA, followed by the Sendai Framework for Disaster Risk Reduction 2015-2030 (UNISDR 2015). By providing expected outcomes, strategic goals, and priorities of action as practical guidelines for reducing disaster risk, the HFA and the Sendai Framework help local government leaders build the resilience of their cities.

The MCR campaign launched in 2010 encourages local governments to adopt its guiding practices in building resilience. In its "How to Make Cities More Resilient: A Handbook for Local Government Leaders," UNISDR (2012b) identifies 10 essential tasks that local government leaders need to perform to ensure that hazard risks are reduced and adaptive capacities are built in their cities. These essential tasks are: (1) organization and coordination for resilience; (2) providing a budget and incentives for risk reduction; (3) updating hazard and vulnerability data; (4) investing in risk reducing infrastructure; (5) assessing the safety of all schools and health facilities; (6) enforcing riskcompliant building regulations and land use planning; (7) ensuring education programs and training on disaster risk reduction; (8) protecting ecosystems and natural buffers to mitigate hazards and adapt to climate change; (9) installing early warning systems and emergency management capacities; and (10) ensuring that the needs and participation of the affected population are at the center of reconstruction. While disaster risk reduction and resilience building require a team effort that incorporates all related parties-including local government, academia, citizens, community groups, private sector/business communities, professional groups, civil society, nongovernmental organizations, national government authorities and parliamentarians, and international organizations (UNISDR 2012b) — it is the direct responsibility of local government 
leaders to lead the implementation of disaster risk reduction and resilience building programs and turn such efforts into realistic outcomes.

\subsection{Factors Affecting Disaster Resilience}

Disaster resilience has been empirically examined by researchers for many years. The aim of previous studies was mainly to explain why some communities did better or were successful in responding to and bouncing back from large-scale disasters while others failed.

Findings from previous studies have suggested that a community's disaster resilience can be attributed to a variety of factors: a sense of community; problem-focused coping style; self- or collective efficacy (Tobin 1999; Paton and Johnston 2001) social support or social capital (Buckland and Rahman 1999; Buckle et al. 2003; Rhinard and Sundelius 2010) citizen participation in voluntary organizations (Childs 2008) local leaders (Buckle et al. 2003; Paton and Auld 2006; Boin 2010) disaster management policies, plans, and practices (Manyena 2006) process-oriented hazard mitigation policies (Birkland 2010) organizational preparedness (Kendra and Wachtendorf 2003) cooperation (Rhinard and Sundelius 2010) learning and communication (Buckle et al. 2003; Comfort et al. 2010) local knowledge, experience, value, and culture (Jang and LaMendola 2006; Jang and Wang 2009) infrastructure and lifelines (Cutter et al. 2008, 2010; Johnston et al. 2006) and the demographic characteristics of a community (Cutter et al. 2008; Lahad 2008).

Drawing on previous research and literature, Khunwishit (2013) categorized disaster resilience factors into six groups: psychological, infrastructural, socioeconomic, social-capability and social capital, managerial and organizational, and cultural factors. Leadership, the primary focus of this study, was grouped into the managerial and organizational group of factors.

\subsection{Leadership and Disaster Resilience}

There seems to be a common understanding among emergency management scholars that leadership can promote disaster resilience. Boin (2010), for example, argues that public leaders are responsible for creating social bonds between a community's members and their trust in societal institutions, which is the primary condition for building disaster resilience in a community. In addition to creating such social bonds, the job of local leaders is to put in place the basic response mechanisms to disasters and to make sure that potential responders are trained, all potential crisis management actors exercise on a regular basis, planning is continuous, mobile information-gathering units are in place, and administrative capacity exists to organize long- term reconstruction efforts (Boin 2010). If these tasks are accomplished, the disaster resilience of a community can be improved.

Other researchers have found that leadership affects organizational resilience and team performance under crisis. Huettermann et al. (2014), for example, examined the effect of leadership on team identification of UN Peacebuilding team members and found four dimensions of leadership that positively affect team identification: providing guidance, encouraging involvement, role modeling, and administering teamwork. These four leadership behaviors are important because they help promote cooperation among team members and mitigate dysfunctional team processes (van der Vegt and Bunderson 2005; Huettermann et al. 2014). Another study examined the role of leadership in the context of terrorist attacks. Birkeland et al. (2017) conducted a longitudinal study to assess the impact of a terrorist attack on employees' perceptions of leadership. By analyzing the data collected from a sample of ministerial employees following the 2011 Oslo bombing, the results showed that, during a crisis, being supportive, fair, and empowering were the three leadership behaviors that helped increase organizational resilience. This finding is consistent with what was found by Peus (2011) and Farooq Malik et al. (2014).

Findings from these studies clearly suggest that disaster resilience can be enhanced by leadership. However, the types of leadership qualities, characteristics, and abilities that help promote disaster resilience of cities are not yet clearly understood and need to be empirically examined. To help answer that question, we need to compare the two major approaches to disaster management: the traditional approach and the disaster risk reduction approach.

In the traditional approach to disaster management, in which emergency response and disaster recovery are the primary focus, community or city leaders are expected to lead in managing emergency response operations, such as emergency warning, search and rescue, evacuation, sheltering, mass medical care, and the media. By position and responsibility, he or she will take a commanding role in responding to emergency incidents. From this perspective, crisis leadership is the type of leadership that best suits local government leaders.

To lead effectively during a crisis, leaders need to have the ability to build trust, change corporate mindset, identify vulnerabilities, make wise and rapid decisions, act courageously, and help promote change (James and Wooten 2004). In addition, to ensure successful response operations, emergency managers need to play a collaborative role. As Waugh and Streib (2006) suggest, successful responses to an emergency depend on how well organizations, governments, and entities in all sectors and at all levels collaborate. The role of a leader is to be a 
collaborator who brings together efforts from all stakeholders in the emergency response operations.

In the disaster risk reduction approach, however, leaders are expected to do more than just respond to an emergency. This approach to disaster management emerged with the HFA in 2005. It strives to create a safe and sustainably growing city by means of reducing disaster risk and building resilience for the city. To achieve the goals of minimizing disaster risk and increasing resilience, local government leaders need to ensure that the following priorities of action are fully implemented and continually maintained: ensuring that disaster risk reduction is a priority with a strong institutional basis for implementation; identifying, assessing, and monitoring disaster risks and enhancing early warning; using knowledge, innovation and education to build a culture of safety and resilience; reducing the underlying risk factors; and strengthening disaster preparedness for effective response (UNISDR 2005). In the 2015 Sendai Framework these priorities of action were adjusted to accelerate the progress of disaster risk reduction and resilience building. These new priorities of action include: understanding disaster risk; strengthening disaster risk governance to manage disaster risk; investing in disaster risk reduction for resilience; and enhancing disaster preparedness for effective response and to "Build Back Better" in recovery, rehabilitation, and reconstruction (UNISDR 2015),

Berkowitz (2015) suggests that the tasks of the Chief Resilience Officer (CRO), a city's key person responsible for developing and implementing resilience strategy, reducing disaster risk, and building resilience for a city should include: (1) working across government departments to help a city improve internal communication, address its own complexities, and encourage new collaboration; (2) bringing together a wide array of stakeholders to learn about the city's challenges and build support for individual initiatives that help the city build resilience; (3) leading the development of the city's resilience strategy, which unites the city's key resilience challenges and opportunities, and spurs the city to act on them; and (4) ensuring the city applies a resilience lens to everything it does so that resources are leveraged holistically and projects are planned for synergy. To accomplish these tasks of reducing disaster risk and building resilience, Salkin (2014, p. 1) suggests that, a city's Chief Resilience Officer needs to rely on the following abilities:

1. Ability to inspire, influence, and enlist colleagues and city residents to activate the city's resilience strategy.

2. Ability to understand their community and local setting and to establish and maintain strong engagement from municipal leaders, city residents, and key stakeholders.
3. Ability to represent the city in global forums in order to share information, ideas, best practices, and more effectively develop innovative solutions.

4. Ability to communicate with and be effective within multiple sectors and disciplines such as transportation, energy, healthcare, housing, education, and community engagement.

5. Ability to be resourceful and willing to experiment, pursue new ideas, and take risks.

6. Ability to communicate effectively to drive the resilience conversation in the city and engage stakeholder support.

7. Ability to manage multiple streams of work and multiple relationships in an effective and efficient manner.

As the disaster management paradigm has evolved from a traditional approach that focuses on managing an emergency to a more proactive approach that emphasizes the reduction of disaster risk and building resilience, we argue that it is these abilities that help local government leaders get the tasks of disaster risk reduction and resilience building done effectively. Based on related literature and concepts elaborated above, we refer to these abilities as "disaster resilience leadership" (DRL). We also hypothesize that DRL is a significant predictor of a city's disaster resilience. We examined DRL among local government leaders in Thailand, which, in our research, not only referred to municipality mayors, but also included other highly positioned administrators who are directly responsible for or assigned to carrying out disaster management functions, such as deputy mayors, municipal clerks, and emergency managers. We then tested the effect of DRL on each city's disaster resilience.

\section{Methods}

Investigating flood resilience building progress and contributing factors in this research involves multiple steps of analysis. This includes sampling, designing a survey questionnaire, collecting data, measuring two important variables (disaster resilience and disaster resilience leadership), screening data, obtaining descriptive statistics, and performing multiple regression analysis.

\subsection{Data and Sample}

To examine the effect of leadership on flood disaster resilience, we developed a questionnaire using the results of a qualitative data analysis obtained from interviews with mayors and representatives of eight municipalities from five regions of Thailand. We supplemented the questions in 
our survey questionnaire with the 10 Essentials for Making Cities Resilient developed by UNISDR and also drew on the concept of Chief Resilience Officer introduced by Salkin (2014). Our questionnaire consisted of three parts: (1) respondent information and municipality profile; (2) the 10 Essentials of City Resilience (which reflected the progress of disaster risk reduction and resilience building); and (3) the Disaster Resilience Leadership abilities of local government leaders. The survey questionnaires were distributed to 367 municipalities across Thailand. From August to November 2016, 104 questionnaires were returned to us, a return rate of about $28 \%$. Four cases were subsequently removed, resulting in a final sample size of 100 .

Of these 100 cases, $93 \%$ were subdistrict municipalities, $5 \%$ were town municipalities, and $2 \%$ were city municipalities. In Thailand's local government administrative system, the type of municipality reflects population size, area, budget, and income of the city. Among the three municipality types, the city municipality is the largest and the subdistrict municipality is the smallest. In the sample of 100 municipalities, $50 \%$ were from the northern region, $18 \%$ from the northeast, $16 \%$ from the central region, $9 \%$ from the south, and $7 \%$ from the east. In terms of their risk profile, 34\% were affected by flooding in 2010 and/or 2011 , while $66 \%$ reported that they had not been affected by these two catastrophic disasters.

Respondents consisted of $88 \%$ males and $12 \%$ females; $42 \%$ were mayors, $4 \%$ were deputy mayors, $32 \%$ were municipal clerks, and $22 \%$ held other positions involved with disaster management functions. Respondents had mixed levels of education and fields of study: $47 \%$ had a bachelor's degree, and 53\% had a master's or higher degree (97\% of respondents reported that they graduated with a social science degree, $3 \%$ reported they graduated with a science degree).

\subsection{Measures}

The main purpose of this research is to examine the relationship between disaster resilience and disaster resilience leadership. Before such a relationship can be tested, it is necessary that these two important concepts are operationalized. The following section discusses how the two concepts are measured.

\subsubsection{Disaster Resilience}

To measure disaster resilience, our dependent variable, we relied on UNISDR's 10 Essentials for Making Cities Resilient. The 10 Essentials provide a comprehensive framework for cities to reduce disaster risk and increase resilience. These 10 essential tasks include:
Essential 1: Put in place organization and coordination to understand and reduce disaster risk, based on participation of citizen groups and civil society. Build local alliances. Ensure that all departments understand their role in disaster risk reduction and preparedness.

Essential 2: Assign a budget for disaster risk reduction and provide incentives for homeowners, low-income families, communities, businesses and the public sector to invest in reducing the risks they face.

Essential 3: Maintain up-to-date data on hazards and vulnerabilities. Prepare risk assessments and use these as the basis for urban development plans and decisions, ensure that this information and the plans for your city's resilience are readily available to the public and fully discussed with them.

Essential 4: Invest in and maintain critical infrastructure that reduces risk, such as flood drainage, adjusted where needed to cope with climate change.

Essential 5: Assess the safety of all schools and health facilities and upgrade these as necessary.

Essential 6: Apply and enforce realistic, risk-compliant building regulations and land use planning principles. Identify safe land for low-income citizens and upgrade informal settlements, wherever feasible.

Essential 7: Ensure that education programs and training on disaster risk reduction are in place in schools and local communities.

Essential 8: Protect ecosystems and natural buffers to mitigate floods, storm surges and other hazards to which your city may be vulnerable. Adapt to climate change by building on good risk reduction practices.

Essential 9: Install early warning systems and emergency management capacities in your city and hold regular public preparedness drills.

Essential 10: After any disaster, ensure that the needs of the affected population are placed at the center of reconstruction, with support for them and their community organizations to design and help implement responses, including rebuilding homes and livelihoods (UNISDR 2012b, p. 25).

We used these 10 essential tasks as the basis for developing 10 questions in Part 2 of the questionnaire that reflect flood risk reduction and resilience building activities implemented by municipalities in Thailand. In our survey questionnaire, respondents were asked to rate the progress they have made in reducing flood risk and building resilience according to these 10 essentials. Using UNISDR scoring scale for assessing a local government's disaster resilience building progress, the respondents were asked to answer each question on a scale from 1 to 5 : 
5 = Comprehensive achievement has been attained, with the commitment and capacities to sustain efforts at all levels.

4 = Substantial achievement has been attained, but with some recognized deficiencies in commitment, financial resources, or operational capacities.

3 = There is some institutional commitment and capacity to achieving DRR, but progress is not comprehensive or substantial.

2 = Achievements have been made but are incomplete, and while improvements are planned, the commitment and capacities are limited.

$1=$ Achievements are minor and there are few signs of planning or forward action to improve the situation (UNISDR 2012b, p. 79).

To capture the concept of flood disaster resilience, the scores from the 10 questions were summed and averaged to create a flood resilience index (FRI), which is a scale variable. Scores of FRI range from 1 to 5, with 1 reflecting the lowest level and 5 reflecting the highest level of each city's flood disaster resilience. Before computing the FRI variable, a reliability test was conducted to evaluate the internal consistency of the 10 questions. Results from the reliability analysis yielded an acceptable value of Cronbach's alpha (.917), suggesting that the selected questions had internal consistency and were acceptable to be used to create the FRI. The inter-item correlation matrix of the questions used to create the FRI is shown in Table 1.

\subsubsection{Disaster Resilience Leadership (DRL)}

The main predictor variable of this study is disaster resilience leadership (DRL). Our concept of DRL was adapted from Berkowitz's (2015) idea of a Chief Resilience Officer's tasks and Salkin's (2014) concept of a Chief Resilience Officer's responsibilities. Our DRL concept is designed specifically to capture the abilities of local government leaders in reducing flood risk and building resilience in Thailand's context. To measure this, we created seven statements for Part 3 of the questionnaire and asked respondents to self-assess their DRL abilities by rating the following 7 statements:

Ability 1: I am able to inspire, influence, and enlist department heads and employees within the municipality office, as well as city residents, to agree on and support the flood risk reduction and resilience building strategy of the city.

Ability 2: I am able to learn and understand the flood risk profile and other local settings of the city, especially those that are related to flood disaster risk, such as the flood hazard, exposure, and vulnerabilities of the city.
Ability 3: I am able to represent the city in a national forum in order to share information, ideas, and best practices in flood risk reduction and resilience building. Ability 4: I am able to work with multiple sectors and disciplines (for example, transportation, energy, healthcare, housing, education, environmental management, construction, public works, law enforcement, social works, and community engagement) and effectively coordinate flood risk reduction and resilience building efforts with all these sectors and disciplines.

Ability 5: I am willing to experiment, pursue new ideas, and take risks.

Ability 6: I am able to communicate effectively to drive the resilience conversation in the city and engage stakeholder support.

Ability 7: I am able to manage multiple streams of work and multiple relationships in an effective and efficient manner.

The respondents were asked to rate each statement on a scale from 1 to $5(1=$ Not at all true of me, $2=$ Slightly true of me, $3=$ Moderately true of me, $4=$ Very true of me, $5=$ Completely true of me). The scores from rating these seven statements were summed and averaged to create a disaster resilience leadership index (DRLI), which is a scale variable. The scores of the DRLI range from 1 to 5 , with 1 reflecting the lowest level and 5 reflecting the highest level of disaster resilience leadership that was possessed by each local government leader participating in our research. Before computing the DRLI, a reliability test was conducted to evaluate the internal consistency of the seven statements. Results from the reliability analysis yielded an acceptable value of Cronbach's alpha (.915), suggesting that these selected statements had internal consistency and were acceptable to be used to create a DRLI.

Although disaster resilience leadership was the main predictor variable we were interested in, we also recognized that the progress of flood risk reduction and resilience building of a city can be affected by other leadership characteristics of local government leaders, such as educational level, work experience (number of years working for the municipality office), and length of residency (number of years the local government leader has resided in the city). Thus, we also included these variables in our model.

\subsection{Data Analysis Strategy}

Data from survey questionnaires were first coded and some items were recoded as appropriate. Missing data, skewness, and kurtosis were then checked to ensure centrality before analysis. After the data were cleaned, new variables were 
Table 1 Inter-item correlation matrix for the flood resilience index (FRI) in Thailand

\begin{tabular}{|c|c|c|c|c|c|c|c|c|c|c|}
\hline & 1 & 2 & 3 & 4 & 5 & 6 & 7 & 8 & 9 & 10 \\
\hline 1 & 1.000 & & & & & & & & & \\
\hline 2 & .498 & 1.000 & & & & & & & & \\
\hline 3 & .656 & .667 & 1.000 & & & & & & & \\
\hline 4 & .533 & .387 & .495 & 1.000 & & & & & & \\
\hline 5 & .528 & .484 & .609 & .683 & 1.000 & & & & & \\
\hline 6 & .421 & .463 & .538 & .584 & .712 & 1.000 & & & & \\
\hline 7 & .495 & .379 & .534 & .476 & .680 & .613 & 1.000 & & & \\
\hline 8 & .418 & .391 & .533 & .542 & .617 & .612 & .756 & 1.000 & & \\
\hline 9 & .489 & .417 & .531 & .400 & .529 & .533 & .552 & .570 & 1.000 & \\
\hline 10 & .506 & .300 & .489 & .455 & .526 & .504 & .497 & .520 & .628 & 1.000 \\
\hline
\end{tabular}

computed as needed (for example, dummy variable, the flood resilience index, the disaster resilience leadership index). Quantitative analysis began with obtaining frequencies and descriptive statistics to explore the personal characteristics of survey respondents, municipality profile, the level of a city's progress of flood resilience building, and the level of disaster resilience leadership of local government leaders. Then, a multiple regression analysis was conducted to test the relationships among selected variables. We analyzed only one model, in which all predictor variables were included and tested at the same time. Besides, Durbin-Watson and VIF values were obtained to check for autocorrelation and collinearity, respectively. Our analyses indicate that there is no autocorrelation in the sample (Durbin-Watson value of 2.124) and no collinearity problem (VIF values for all predictor variables are between 1.034 and 1.316).

\section{Results}

The results are presented in two parts. In the first part, progress in flood resilience building is presented and interpreted. In the second part, multiple regression analysis results are presented and the effect of each predictor variable on flood resilience building progress is briefly discussed.

\subsection{Progress of Flood Resilience Building in Thailand}

The mean score of each flood resilience building activity ranged from 2.59 to 3.22 (Table 2). Activity 4 received the highest mean score $(M=3.22, \mathrm{SD}=1.10)$, activity 6 received the lowest mean score $(M=2.59, \mathrm{SD}=1.03)$. These scores indicate that, since the floods in 2011, municipalities in Thailand have made the most progress on investing and maintaining flood protection systems such as flood drainage, levees, and floodwalls. Less progress has been made on applying and enforcing risk compliant building regulations and land use planning principles, as well as identifying safe land for low-income citizens. These findings imply that, since the worst flooding in 2011, municipalities in Thailand have been more likely to choose structural mitigation strategies than nonstructural measures as the tools for reducing flood risk and building resilience. In addition, when considering the overall mean score $(M=2.92, \mathrm{SD}=.78)$, municipalities in Thailand have made a moderate level of progress in implementing flood resilience building, on average. This suggests that, since 2011, there has been some institutional commitment and capacity to achieving flood risk reduction in these municipalities, but progress has not yet been comprehensive or substantial. Compared to some countries in Asia and Latin America that have made considerable progress in implementing the HFA (Manyena 2016), the progress of disaster risk reduction and resilience building in Thailand has been relatively slow.

In addition, when comparing the overall progress of flood resilience building among the five regions, the data show that, on average, municipalities located in the northern region of Thailand have made the highest level of progress in flood resilience building, followed by municipalities in the central, southern, northeastern, and eastern regions, respectively (Fig. 1). This finding suggests that the impacts of flooding in 2011 also play a part in driving the progress of flood risk reduction and resilience building efforts. Cities located in the northern and central regions of Thailand were much more impacted by a series of floods in 2011 than other regions. As a result, these destructive impacts boosted the awareness of flood risk in those areas 
Table 2 Progress of flood resilience building (FRB) in Thailand by municipality $(N=100)$

\begin{tabular}{|c|c|c|}
\hline FRB activities & $M^{*}$ & $\mathrm{SD} * *$ \\
\hline Put in place organization and coordination to understand and reduce flood risk & 3.13 & .85 \\
\hline $\begin{array}{l}\text { 2. Assign a budget for flood risk reduction and provide incentives for homeowners, low-income families, communities, and } \\
\text { businesses to invest in reducing the risks they face }\end{array}$ & 2.64 & 1.07 \\
\hline 3. Maintain up-to-date data on flood hazards and vulnerabilities and prepare flood risk assessments & 3.03 & .94 \\
\hline 4. Invest in and maintain critical infrastructure that reduces flood risk, such as flood drainage, levees, and floodwalls & 3.22 & 1.10 \\
\hline 5. Assess the safety of all schools and health facilities and upgrade these as necessary & 3.03 & 1.10 \\
\hline $\begin{array}{l}\text { 6. Apply and enforce realistic, risk-compliant building regulations and land use planning principles. Identify safe land for low- } \\
\text { income citizens and upgrade informal settlements, wherever feasible }\end{array}$ & 2.59 & 1.03 \\
\hline 7. Ensure that education programs and training on flood risk reduction are in place in schools and local communities & 2.99 & .99 \\
\hline 8. Protect ecosystems and natural buffers to mitigate floods & 3.07 & 1.03 \\
\hline 9. Install early warning systems and emergency management capacities in your city and hold regular publ & 2.60 & 1.10 \\
\hline 10. Ensure that the needs of the affected population are placed at the center of reconstruction & 2.92 & 1.11 \\
\hline Average mean score of all 10 FRB Activities & 2.92 & .78 \\
\hline
\end{tabular}

$* M=$ value of mean score of flood risk reduction

$* * \mathrm{SD}=$ value of standard deviation of each mean score

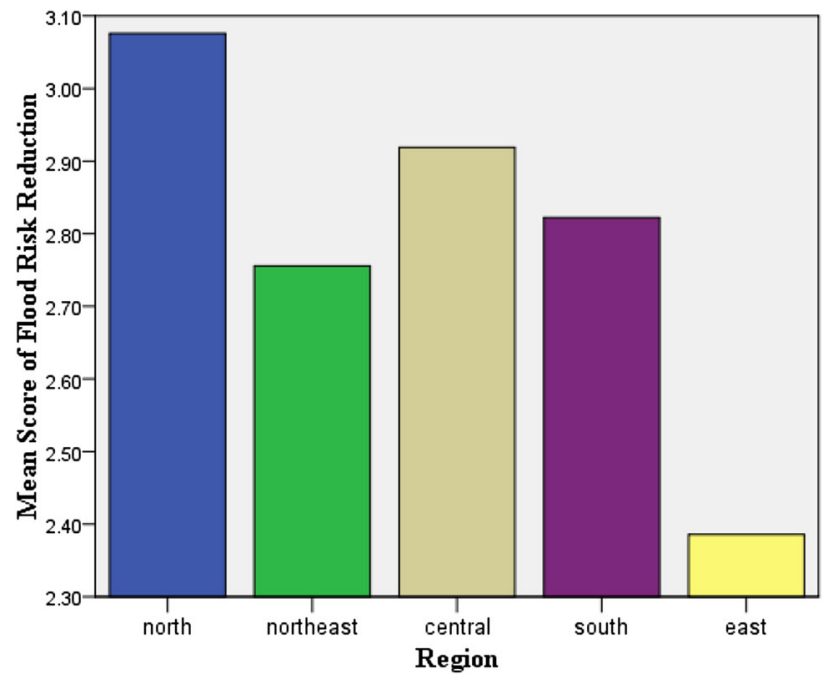

Fig. 1 Flood resilience building (FRB) progress in Thailand by region $(N=100)$

and encouraged the affected municipalities to put more effort into flood risk reduction and resilience building.

\subsection{The Effect of Leadership on Flood Resilience Building Progress in Thailand}

To examine how leadership affects the progress of flood resilience building of a city in Thailand, the dependent variable flood resilience index (FRI) was regressed on 4 predictor variables, which included educational level (dummy), years of work experience (number of years working for the municipality office), years of residency (number of years the local government leader has resided in the city), and disaster resilience leadership index (DRLI). The result was statistically significant $(F=34.834, p<.001)$. Our model explained $59.5 \%$ of the variation in the dependent variable flood resilience index $\left(R^{2}=.595 \times 100=59.5 \%\right)$. The results of the multiple regression analysis are presented in Table 3.

According to the results, as expected, the disaster resilience leadership index had a statistically significant, positive effect on the flood resilience index $(b=.731$, $p<.001)$. This suggests that, controlling for the effects of all other predictors, municipalities whose local government leaders possess a higher level of disaster resilience

Table 3 Results of the multiple regression analysis of the flood resilience index (FRI) on selected variables in Thailand $(N=100)$

\begin{tabular}{lll}
\hline Variables & $b$ & Beta \\
\hline Educational level (undergraduate degree) & .173 & .111 \\
& $(.117)$ & \\
Years of work experience & $.031^{* * *}$ & .265 \\
& $(.009)$ & \\
Years of residency & .005 & .136 \\
& $(.003)$ & \\
Disaster resilience leadership index (DRLI) & $.731^{* * *}$ & .718 \\
& $(.068)$ & \\
Constant & .014 & \\
$R^{2}$ & .595 & \\
\hline
\end{tabular}

$N=100 ; b=$ unstandardized regression coefficient with standard error in parentheses; Beta $=$ standardized regression coefficient $* * * p<.001$ (two-tailed tests) 
leadership tend to have a higher level of progress in flood resilience building. Each one-point score increase in the disaster resilience leadership index was on average associated with a .731-point score increase in the flood resilience index. In addition, our analysis also reveals that the number of years that local government leaders have worked for the municipality office has a statistically significant, positive effect on the progress of flood resilience building ( $b=.031, p<.001)$. However, local government leaders' educational level and years of residency were not found to be significantly predictive of a city's progress in flood resilience building.

\section{Discussion and Conclusion}

Disaster risk reduction and resilience building have become the focus of contemporary disaster management practices. Practitioners and researchers are now more interested in how disaster risk reduction and resilience building can be enhanced. Previous literature and studies suggest that the disaster resilience of a city can be attributable to multiple factors, including leadership. However, the specific leadership qualities thought to promote enhanced resilience have not been empirically examined. Answering this basic question is important, because it sheds light on how local government leaders can contribute to and accelerate efforts in reducing disaster risk and building the resilience of their cities.

To examine the effect of leadership on the disaster resilience of a city, we tested one primary hypothesis using four predictor variables. The results showed that our hypothesis that DRL has a positive effect on a city's progress of flood resilience building was empirically supported. Our findings suggest that municipalities whose local government leaders possess a higher level of DRL tend to make more progress in reducing disaster risk and building resilience for their cities. We also found that years of work experience in the municipality office of local government leaders was predictive of each city's progress in building flood resilience. This indicates that the longer a local government leader has worked for the municipality office, the more progress in disaster risk reduction and resilience building the city can make. Disaster risk reduction and resilience building is an ongoing process and needs continuous improvement. Local government leaders who have worked for the municipality office for a longer period can ensure policy continuation and cooperative relationships among departments within the municipality office and between the municipality office and other organizations. Policy continuation and cooperative relationships are essential for developing and implementing a city's resilience strategy.
In the past, local government leaders were often expected to take a command and control role in responding to an emergency or a disaster. In the current approach to disaster management, local government leaders are expected to proactively perform multiple tasks to reduce disaster risk and increase the resilience of their cities. Thus, a new set of leadership traits is required to perform these tasks effectively. Findings from our research reveal that disaster resilience leadership possessed by local government leaders enhances the resilience of a city. Our DRL model, which is adapted from Salkin's (2014) concept of the Chief Resilience Officer, encompasses seven abilities that are supportive of performing the 10 essential tasks of making cities resilient (UNISDR 2012b) and, thus, of achieving the priorities of action identified in the Sendai Framework.

For example, the DRL ability to learn and understand the risk profile and other local settings of a city (DRL Ability 2) helps local government leaders to better perform the task of updating hazard and vulnerability data and preparing a risk assessment (MCR Essential Task 3), as well as assessing and updating the safety of schools and health facilities (MCR Essential Task 5). Effectively performing such tasks contributes to the achievement of the Sendai Framework's Priority of Action 1 (understanding disaster risk).

The DRL ability to inspire, influence, and enlist department heads and employees within the municipality office, as well as city residents, to agree on and support the disaster risk reduction and resilience building strategy of the city (DRL Ability 1), the DRL ability to work with multiple sectors and to effectively coordinate disaster risk reduction and resilience building efforts with all these sectors (DRL Ability 4), the DRL ability to communicate effectively to drive the resilience conversation in the city and engage stakeholder support (DRL Ability 6), and the DRL ability to manage multiple streams of work and multiple relationships in an effective and efficient manner (DRL Ability 7) help local government leaders to better perform the tasks of applying and enforcing risk compliance building regulations and land use planning principles (MCR Essential Task 6), providing disaster risk reduction training and education programs in schools and communities (MCR Essential Task 7), protecting ecosystems and natural buffers for mitigating hazards and adapting to climate change (MCR Essential Task 8), establishing emergency management capacities and installing early warning systems (MCR Essential Task 9), and putting the needs and participation of the affected population at the center of reconstruction following a disaster (MCR Essential Task 10). Consequently, successfully performing these tasks helps achieve the Sendai Framework's Priority of Action 2 (strengthening disaster risk governance to manage disaster 
risk), Priority of Action 3 (investing in disaster risk reduction for resilience), and Priority of Action 4 (enhancing disaster preparedness for effective response and to "Built Back Better" in recovery, rehabilitation, and reconstruction).

We argue here that the disaster resilience leadership model provides a set of leadership abilities that are supportive of performing the 10 essential tasks for making cities resilient and of achieving priorities of action identified in the Sendai Framework (UNISDR 2015). Thus, in this current paradigm of disaster management, it is this set of leadership abilities that is more applicable to leading and organizing a city's efforts. This is because successful disaster risk reduction and resilience building for a city rely more on the communication, coordination, and collaboration abilities of local government leaders than the ability to command and control.

The findings of our research inform local government leaders on how they can significantly promote disaster resilience of their cities. The tasks of reducing disaster risk and building resilience for a city are ongoing in nature. Thus, implementing disaster risk reduction and resilience building initiatives, projects, and activities requires continuing, consistent, and persistent efforts from multiple stakeholders and sectors. Hence, the role of a local government leader is more than just to exercise command and control as he/she does in emergency response. Instead, he/ she needs to be a project initiator, a resources mobilizer, an efforts coordinator or collaborator (Waugh and Streib 2006), a teamwork promoter, and a driver of the city resilience strategy at the same time. To accomplish all these challenging tasks, local government leaders need to have multiple abilities. Based on previous literature and research, our disaster resilience leadership (DRL) model identifies specific abilities that are most supportive of effectively carrying out disaster risk reduction and resilience building tasks. More importantly, the results of our empirical study show that local government leaders who possess a higher level of disaster resilience leadership (DRL) can contribute significantly to the progress of disaster risk reduction and resilience building efforts. Thus, we recommend that developing DRL abilities in local government leaders is essential if a city wants to achieve its goals in reducing disaster risk and building resilience.

One way to develop DRL abilities for local government leaders is to provide training and education. The seven abilities identified in our DRL model can serve as guidelines for designing DRL competencies that fit with the cultural and local contexts of each city or country. Cities can work with local universities or other academic institutions to design DRL competencies and provide the DRLbased training. It is also recommended that DRL-based training should not only be provided to municipality mayors or city managers, but should also be extended to emergency management personnel, heads of all departments, public agencies and representatives of private organizations, and community groups involved in the disaster risk reduction and resilience building of a city. If the representatives of all relevant organizations and stakeholders have disaster resilience leadership abilities, resources used for disaster risk reduction and resilience building efforts can be mobilized in a more holistic way and, most importantly, more progress can be made.

Acknowledgements This research project has been financially supported by Academic Research Division, The Thailand Research Fund (TRF) (Grant Number TRG5880127) and Prince of Songkla University. We greatly appreciate this support. The findings, conclusions, and recommendations are those of the authors and do not necessarily reflect the views of the funding agencies.

Open Access This article is distributed under the terms of the Creative Commons Attribution 4.0 International License (http://crea tivecommons.org/licenses/by/4.0/), which permits unrestricted use, distribution, and reproduction in any medium, provided you give appropriate credit to the original author(s) and the source, provide a link to the Creative Commons license, and indicate if changes were made.

\section{References}

Berkowitz, M. 2015. What a chief resilience officer does. http:// webcache.googleusercontent.com/search?q=cache:yvvkTc1dSJk J:www.100resilientcities.org/blog/entry/what-is-a-chief-resilienc e-officer $1+\& c d=1 \& h l=e n \& c t=c \operatorname{lnk} \& g l=t h$. Accessed 21 May 2017.

Birkeland, M.S., M.B. Nielsen, M.B. Hansen, S. Knardahl, and T. Heir. 2017. The impact of a workplace terrorist attack on employees' perceptions of leadership: A longitudinal study from pre-to post-disaster. The Leadership Quarterly 28(5): 659-671.

Birkland, T.A. 2010. Federal disaster policy: Learning, priorities, and prospects for resilience. In Designing resilience: Preparing for extreme events, ed. L.K. Comfort, A. Boin, and C.C. Demchak, 106-128. Pittsburgh, PA: University of Pittsburgh Press.

Boin, A. 2010. Designing resilience: Leadership challenges in complex adaptive systems. In Designing resilience: Preparing for extreme events, ed. L.K. Comfort, A. Boin, and C.C. Demchak, 129-142. Pittsburgh, PA: University of Pittsburgh Press.

Buckland, J., and M. Rahman. 1999. Community-based disaster management during the 1997 Red River Flood in Canada. Disasters 23(3): 174-191.

Buckle, P., G. Marsh, and S. Smale. 2003. The development of community capacity as applying to disaster management capability (project 14/2002). Mt Macedon, Australia: Emergency Management Australia.

Childs, I. 2008. Emergence of new volunteerism: Increasing community resilience to natural disasters in Japan. In The phoenix of natural disasters: Community resilience, ed. K. Gow, and D. Paton, 171-180. New York City, NY: Nova Science Publishers.

Comfort, L.K., N. Oh, G. Ertan, and S. Scheinert. 2010. Designing adaptive systems for disaster mitigation and response: The role of structure. In Designing resilience: Preparing for extreme events, ed. L.K. Comfort, A. Boin, and C.C. Demchak, 33-61. Pittsburgh, PA: University of Pittsburgh Press. 
Cutter, S.L., L. Barnes, M. Berry, C.G. Burton, E. Evans, E. Tate, and J. Webb. 2008. A place-based model for understanding community resilience to natural disasters. Global Environmental Change 18(4): 598-606.

Cutter, S.L., C.G. Burton, and C.T. Emrich. 2010. Disaster resilience indicators for benchmarking baseline conditions. Journal of Homeland Security and Emergency Management 7(1): 1-22.

Farooq Malik, O., H. Abdullah, and J. Anak Uli. 2014. The effects of terrorism on work attitudes and behaviors: A literature review and a proposed model. Journal of Aggression Conflict and Peace Research 6(3): 143-163.

Huettermann, H., S. Doering, and S. Boerner. 2014. Leadership and team identification: Exploring the followers' perspective. The Leadership Quarterly 25(3): 413-432.

James, E.H., and L.P. Wooten. 2004. Leadership in turbulent times: Competencies for thriving amidst crisis. Darden Business School Working Paper No.04-04, University of Virginia, Charlottesville, VA. http://195.130.87.21:8080/dspace/bitstream/ 123456789/103/1/Leadership\%20in\%20turbulent\%20times\%20 Hayes.pdf. Accessed 19 Jan 2017.

Jang, L., and W. LaMendola. 2006. The Hakka spirit as a predictor of resilience. In Disaster resilience: An integrated approach, ed. D. Paton, and D. Johnston, 174-189. Springfield, IL: Charles C. Thomas Publisher.

Jang, L., and J. Wang. 2009. Disaster resilience in a Hakka community in Taiwan. Journal of Pacific Rim Psychology 3(2): 55-65.

Johnston, D., J. Becker, and J. Cousins. 2006. Lifelines and urban resilience. In Disaster resilience: An integrated approach, ed. D. Paton, and D. Johnston, 40-65. Springfield, IL: Charles C. Thomas Publisher.

Kendra, J.M., and T. Wachtendorf. 2003. Elements of resilience after the World Trade Center disaster: Reconstructing New York City's emergency operations center. Disasters 27(1): 37-53.

Khunwishit, S. 2013. Community resilience in Thailand: A case study of flood response in Nakhonsawan City Municipality. Doctoral dissertation. University of North Texas, Denton, Texas, USA. http://digital.library.unt.edu/ark:/67531/metadc271841/. Accessed 9 Jun 2017.

Lahad, M. 2008. Post traumatic responses in disasters: A community perspective. In The phoenix of natural disasters: Community resilience, ed. K. Gow, and D. Paton, 33-46. New York City, NY: Nova Science Publishers.

Manyena, B. 2006. The concept of resilience revisited. Disasters 30(4): 433-450.

Manyena, B. 2016. After Sendai: Is Africa bouncing back or bouncing forward from disasters? International Journal of Disaster Risk Science 7(1): 41-53.

Paton, D., and T. Auld. 2006. Resilience in emergency management: Managing the flood. In Disaster resilience: An integrated approach, ed. D. Paton, and D. Johnston, 267-287. Springfield, IL: Charles C. Thomas Publisher.
Paton, D., and D. Johnston. 2001. Disasters and communities: Vulnerability, resilience and preparedness. Disaster Prevention and Management 10(4): 270-277.

Peus, C. 2011. Money over man versus caring and compassion? Challenges for today's organizations and their leaders. Journal of Organizational Behavior 32(7): 955-960.

Rhinard, M., and B. Sundelius. 2010. The limits of self-reliance: International cooperation as a source of resilience. In Designing resilience: Preparing for extreme events, ed. L.K. Comfort, A. Boin, and C.C. Demchak, 196-219. Pittsburgh, PA: University of Pittsburgh Press.

Rodin, J. 2014. The resilience dividend: Being strong in a world where things go wrong. New York: Public Affairs.

Salkin, A. 2014. What is a chief resilience officer? http://www. 100resilientcities.org/blog/entry/what-is-a-chief-resilience-office r\#/-_/. Accessed 19 Jan 2017.

Tobin, G.A. 1999. Sustainability and community resilience: The holy grail of hazards planning. Environmental Hazards 1(1): 13-26.

UNISDR (United Nations International Strategy for Disaster Reduction). 2005. Hyogo framework for action 2005-2015: Building the resilience of nations and communities to disasters. http:// www.unisdr.org/files/1037_hyogoframeworkforactionenglish. pdf. Accessed 22 Jul 2017.

UNISDR (United Nations International Strategy for Disaster Reduction). 2012a. Disaster impacts 2000-2012. http://www.preven tionweb.net/files/31737_20130312disaster20002012copy.pdf. Accessed 22 Nov 2013.

UNISDR (United Nations International Strategy for Disaster Reduction). 2012b. How to make cities more resilient: A handbook for local government leaders. http://www.unisdr.org/files/26462_ handbookfinalonlineversion.pdf. Accessed 22 Jul 2017.

UNISDR (United Nations International Strategy for Disaster Reduction). 2015. Sendai framework for disaster risk reduction 20152030. https://www.unisdr.org/files/43291_sendaiframeworkfordr ren.pdf. Accessed 22 Jul 2017.

UNISDR (United Nations International Strategy for Disaster Reduction). 2017. Making cities resilient: My city is getting ready. http://www.unisdr.org/campaign/resilientcities/home/index. Accessed 26 Feb 2018.

Van Der Vegt, G.S., and J.S. Bunderson. 2005. Learning and performance in multidisciplinary teams: The importance of collective team identification. Academy of Management Journal 48(3): 532-547.

Waugh, W.L., and G. Streib 2006. Collaboration and leadership for effective emergency management. Public Administration Review 66(s1): 131-140.

World Bank. 2017. Disaster risk reduction progress score: 2011. http://data.worldbank.org/indicator/EN.CLC.DRSK.XQ. Accessed 19 May 2017. 